\title{
Educação Infantil e o protagonismo da criança: diferentes cenários
}

\section{Infantile Education and the protagonism of the child: different scenarios}

\section{Educación Infantil y el protagonismo de los(as) niños(as): diferentes escenarios}

\author{
Marta Regina Brostolin ${ }^{1}$
}

DOI: http://dx.doi.org/10.20435/serie-estudos.v23i49.1130

\begin{abstract}
Resumo: A infância caracteriza-se como uma categoria histórica e social. A estrutura da sociedade, as condições de vida e de inserção da criança em cada contexto social, econômico, político e cultural é que vão tecer as diferentes concepções de infância e as diversas formas de ser criança. A partir dessa perspectiva, o presente texto, resultante de uma revisão de literatura, tem por objetivo refletir e discutir a trajetória, as políticas públicas e a legislação referentes ao atendimento à criança no percurso da história, num primeiro cenário. No segundo, trata a criança como um sujeito de direitos, protagonista e ator social que produz e reproduz cultura e, no terceiro cenário, aborda a Base Nacional Comum Curricular da Educação Infantil fazendo uma breve contextualização do momento atual pelo qual a educação brasileira passa. Conclui-se que, para além das políticas de educação infantil, é importante pensar em outras políticas quando se trata do atendimento integral à criança, e aqui se incluem aspectos relacionados não só à educação, como também à saúde, à cultura e à proteção, o que torna necessária a interlocução, com outras áreas dos serviços públicos e outras ações que não são específicas da educação.
\end{abstract}

Palavras-chave: Educação Infantil; políticas públicas; protagonismo da criança.

Abstract: Childhood is characterized as a historical and social category. The structure of society, the conditions of life and insertion of the child in each social, economic, political and cultural context is what will weave the different conceptions of childhood and the various ways of being a child. From this perspective, the present text resulting from a literature review aims to reflect and discuss the trajectory, public policies and legislation regarding child care in the course of history in a first scenario. In the second, it treats the child as a subject of rights, protagonist and social actor who produces and reproduces culture and, in the third scenario, approaches the National Basic Curriculum of Child Education, making a brief contextualization of the current moment by which Brazilian education passes. It is concluded that in addition to child education policies, it is important to think about other policies when it comes to comprehensive child care, and it includes aspects

\footnotetext{
${ }^{1}$ Universidade Católica Dom Bosco, Campo Grande, Mato Grosso do Sul, Brasil.
} 
related not only to education, but also health, culture and protection, which makes it necessary to interlocate with other areas of public services and other actions that are not specific to education.

Keywords: Infant Education; public policy; protagonism of the child.

Resumen: La infancia se caracteriza como una categoría histórica y social. La estructura de la sociedad, las condiciones de vida y de inserción de los(as) niños(as) en cada contexto social, económico, político y cultural es lo que define las diferentes concepciones de infancia y las diversas formas de ser niño(a). A partir de esa perspectiva, el presente texto resultante de una revisión de literatura, tiene el objetivo de reflexionar y discutir la trayectoria, políticas públicas y legislación referentes al cuidado de los(as) niños(as) en el transcurso de la historia en un primer escenario. En segundo escenario, trata al(a la) niño(a) como sujeto de derechos, protagonista y actor social que produce y reproduce cultura y, como tercer escenario, aborda la Base Nacional Común Curricular de la Educación Infantil haciendo una breve contextualización del momento actual por el que pasa la educación brasileña. Se concluye que, además de las políticas de educación infantil, es importante pensar en otras políticas cuando se trata de la atención integral a los(as) niños(as) y, aquí se incluyen aspectos relacionados no solo a la educación, sino también, a la salud, a la cultura y a la protección, lo cual hace necesaria la interlocución, con otras áreas de los servicios públicos y otras acciones que no son específicas de la educación.

Palabras clave: Educación Infantil; políticas públicas; protagonismo de los(as) niños(as).

\section{INTRODUÇÃO}

A infância caracteriza-se como uma categoria histórica e social. A estrutura da sociedade, as condições de vida e de inserção da criança em cada contexto social, econômico, político e cultural é que vão tecer as diferentes concepções de infância e as diversas formas de ser criança.

Nessa perspectiva, a história do atendimento à criança no Brasil é marcada por desigualdades de uma sociedade estratificada. Da caridade à filantropia, esteve presente a domesticação das classes populares, seja pela disciplina, pela moralização e ou visão médico-higienista, em detrimento do afetivo, cognitivo e cultural.

De alguma forma, a modernidade instituiu uma infância separada do mundo "adultocêntrico" com foco no que a criança não tem, e não vista como um ser em movimento e presente.

Atualmente, a criança passa a ser pensada cada vez mais a partir do que ela é, do que ela sabe, do que ela pode fazer, das suas capacidades, das suas formas de construir cultura. Essa é a grande mudança na concepção de criança e infância nos últimos 30 anos. A criança é pensada como protagonista, ator social, sujeito de direitos. 
Nessa perspectiva, esse texto redigido para atender ao convite para participar da Mesa-Redonda "Educação Infantil e a construção de políticas públicas: currículo e a Base Nacional Comum Curricular", no GT 7 - Educação da criança de zero a seis anos, no Encontro da ANPED-CO, realizado de 6 a 9/11/2016, na UNB/Brasília, passa por reformulações para compor esse Dossiê.

Portanto o texto objetiva refletir e discutir a trajetória, políticas públicas e legislação referente ao atendimento à criança no percurso da história, num primeiro cenário. No segundo, trata a criança como um sujeito de direitos, protagonista e ator social que produz e reproduz cultura e, no terceiro cenário, aborda a Base Nacional Comum Curricular da Educação Infantil e faz uma breve contextualização do momento atual pelo qual a educação brasileira passa.

\section{PRIMEIRO CENÁRIO - EDUCAÇÃO INFANTIL: TRAJETÓRIA, POLÍTICAS E LEGISLAÇÃO}

Segundo Kramer (2011), desde o descobrimento até o final do século XIX, pouco se fazia no país tanto no que se refere à proteção jurídica quanto a alternativas de atendimento com intuito de proteger a criança. Não havia interesse por parte das administrações públicas, e as alternativas, até então, caracterizavam-se pela fragmentação das ações da filantropia e caridade de diferentes grupos privados.

Nas primeiras décadas do Século XX, se iniciam os ganhos de proteção à infância do ponto de vista jurídico, e um conjunto de leis resultou da reivindicação de grupos técnico-profissionais, tais como: os médicos ligados à saúde pública e à recente pediatria, uma vez que estavam preocupados com a higiene infantil, ou seja, com a assistência médica; os juristas interessados em codificações ${ }^{2}$ e instituições de abrigo e "correção" de jovens, com a guarda dos menores e o atendimento aos abandonados e delinquentes; e o movimento operário, que reivindicava uma legislação trabalhista, incluindo o limite do trabalho infantil, não só com relação à idade, mas quanto ao trabalho insalubre e prejudicial ao desenvolvimento humano (KRAMER, 2011).

Em 1902, a apresentação de um projeto legislativo defendendo o direito do menor, desdobrou-se em várias iniciativas, entre elas, o Projeto de Proteção

\footnotetext{
${ }^{2}$ Ato ou efeito de codificar - reunir em, ou reduzir a código.
} 
ao Menor, de Mello Mattos, transformado na Lei n. 5.083, de 1 을 de dezembro de 1926, o que resultou na promulgação do Código de Menores, pelo Decreto Executivo n. 17.943-A, de 12/10/1927 (BROSTOLIN; ROSA, 2014, p. 45).

O Código de Menores fazia uma distinção entre as duas categorias de assistidos: as "crianças" e os "menores". Outra distinção, estabelecida no Código, deu-se entre a "assistência" e a "proteção. A partir dessa distinção, foram constituídos dois setores específicos: no Ministério de Educação e Saúde, o Departamento Nacional da Criança (DNCr) ${ }^{3}$ e, no Ministério de Justiça e Negócios Interiores, o Serviço de Assistência aos Menores (SAM) ${ }^{4}$. Assim, houve um desmembramento das ações do Juizado de Menores para o SAM e o dos médicos partidários de modelos assistenciais para o DNCr.

Com a extinção do SAM anos depois, suas funções foram assumidas pela Fundação Nacional do Bem-Estar do Menor (FUNABEM), vinculada, inicialmente, diretamente à Presidência da República e, em seguida, ao Ministério da Previdência e Assistência Social. O atendimento aos menores ficava a cargo das Fundações Estaduais do Bem-Estar do Menor (FEBEMs), cuja atuação autoritária esteve estampada em todos os jornais do país. E o DNCr, na década de 1960, teve diversos de seus serviços absorvidos pelo Ministério da Saúde e, posteriormente, foi transformado em Coordenação de Proteção Materno-Infantil (KRAMER, 2011).

Durante a década de 1940, outro órgão criado foi a Legião Brasileira de Assistência (LBA), vinculada ao governo federal, que visava prestar assistência a diferentes segmentos da população entre os quais o das crianças de zero a seis anos, com atendimento em Creche. Esse órgão consolidou-se, através de suas obras assistenciais, suplementando a previdência social nos casos em que esta não cobria.

A LBA transformou-se em Fundação, na década de 1970, e passou a executar o Projeto Casulo, que objetivava atender, com baixo custo, ao maior número possível de crianças. Foi implantado em vários Estados e municípios. O Casulo estava inserido no Programa Assistência (Subprograma Assistência ao Menor). A LBA foi extinta no início da década de 1990, tendo suas ações substituídas pela comunidade solidária nessa mesma época (KRAMER, 2011).

\footnotetext{
${ }^{3}$ Criado em 1940 destinado a coordenar atividades relativas à proteção à infância, maternidade e adolescência.

${ }^{4}$ Criado um ano depois do DNCr, voltado para o atendimento de menores de 18 anos.
} 
Quanto às leis educacionais, a Lei de Diretrizes e Bases n. 4.024/61 fez referência à educação da criança de zero a seis anos de idade, considerando-a inclusa no grau primário. Os Artigos 23 e 24 fixavam sua finalidade: "destinar-se aos menores de até sete anos e o local a ser ministrada: em escolas maternais e jardins de infância". Previam, também, que as empresas que tivessem a seu serviço mães, cujos filhos fossem menores de sete anos, deveriam se organizar e manter instituições pré-primárias. A Lei n. 5.692/71 pouco modificou o que já constava na 4.024/61. O § 2o do Artigo 19 enfatizava que os sistemas de ensino deveriam velar para que as crianças menores de sete anos recebessem educação conveniente em escolas maternais, jardins de infância ou em instituições equivalentes. O Artigo 61 chamava a atenção dos sistemas de ensino para que estimulassem as empresas que tivessem mães de menores de sete anos de idade a manter "educação que preceda o ensino de 1o grau" (BROSTOLIN; ROSA, 2014, p. 54).

O que se percebe é que apesar de constar na legislação educacional desde 1961, foi a partir da década de 1970 que as políticas públicas começaram incipientemente, a ampliar o atendimento, em especial às crianças de quatro a seis anos. Foi instituída pelo Ministério de Educação e Cultura (MEC), a Coordenadoria de Educação Pré-escolar (COEPRE). Esta viria coordenar a oferta da pré-escola para o grupo de quatro a seis anos, ficando o grupo de zero a três vinculado a programas assistencialistas, sem uma instância específica de coordenação e supervisão. Kramer (2011) evidencia que o trabalho dessa Coordenadoria resultou no "Diagnóstico Preliminar da Educação Pré-escolar no Brasil", e então foram realizados alguns seminários, com o objetivo de estabelecer os princípios gerais que norteassem um programa de educação pré-escolar para o país.

Em 1987, extinguiu-se a COEPRE, e a educação Pré-escolar passou a ser coordenada pela Secretaria de Ensino Básico (SEB) do MEC. Finalmente, em 1990, criou-se a Coordenadoria Geral de Educação Infantil (COEDI), com a responsabilidade de estabelecer diretrizes para o atendimento às crianças de zero a três, em creche, e de quatro a seis anos, em pré-escola e, também, com a finalidade de oferecer subsídios para uma educação com qualidade, reafirmando, assim, a importância dessa etapa educacional, o significado da infância e o direito ao atendimento educacional nos primeiros anos de vida. Essa Coordenadoria ocupa-se das políticas de educação infantil, desde então. 
No delineamento das políticas públicas desenvolvidas, as pesquisas produzidas em diversas áreas do conhecimento e os movimentos sociais tiveram papel relevante. Foram anos de luta em torno da Constituição da República Federativa do Brasil que, aprovada em 5 de outubro de 1988, veio afirmar o direito das crianças à Educação Infantil em creches e pré-escolas, o dever do Estado de assegurar as vagas e a opção da família quanto à frequência.

Essa conquista foi reiterada pelo Estatuto da Criança e do Adolescente (Lei n. 8.069, de 13 de julho de 1990), fruto de imensa mobilização nacional, que recolheu mais de um milhão de assinaturas de cidadãos brasileiros de todo o país, bem como pela Lei de Diretrizes e Bases da Educação Nacional, que reconheceu a Educação Infantil como primeira etapa da Educação Básica, Lei n. 9.394, de 20 de dezembro de 1996.

Em 1993, o MEC delineou pela primeira vez uma Política Nacional de Educação Infantil propondo diretrizes norteadoras de propostas pedagógicas voltadas ao desenvolvimento da criança, às interações entre as crianças, à autoestima e à identidade, ao respeito à diversidade de expressões culturais, ao brincar como modo privilegiado de aprendizagem e desenvolvimento, ao trabalho cooperativo (BRASIL, 1994).

Este documento veio acompanhado de uma série de outros que ficaram conhecidos como os documentos das "Carinhas" 5 . E, entre eles, o documento "Critérios para um atendimento em creches que respeite aos direitos fundamentais das crianças", que reiterou tais objetivos, estabelecendo critérios para garantir a qualidade na Educação Infantil, particularmente nas creches: critérios de organização e funcionamento, focalizando as práticas com as crianças; critérios relativos à definição de diretrizes e normas políticas, programas e sistemas de financiamento de creches (BROSTOLIN; ROSA, 2014).

Em 1998, foi publicado o documento do Referencial Curricular Nacional para a Educação Infantil, muito questionado pelos pesquisadores da infância por ser um documento voltado para crianças maiores da educação infantil, sem especificações para os bebês e os muito pequenos. Esse material, apresentado

\footnotetext{
${ }^{5}$ Em 1994 foi lançado: Educação Infantil no Brasil: situação atual; Por uma Política de Formação do Profissional de Educação Infantil. Em 1995, Critérios para um atendimento em creches que respeite os direitos fundamentais das crianças. Em 1996, Propostas Pedagógicas e Currículos em Educação Infantil.
} 
em três volumes, se configurou como um documento contendo recomendações para as práticas pedagógicas.

Logo em seguida, o Conselho Nacional de Educação instituiu as Diretrizes Curriculares Nacionais para a Educação Infantil - Parecer CNE/CEB n. 22/1998, Resolução CNE/CEB n. 1/1999. Com força de Lei, as Diretrizes elaboradas naquele momento tiveram o mérito de consolidar a discussão em torno da importância da qualidade da Educação Infantil como inequívoco requisito para o cumprimento do direito das crianças.

Em 2006, o MEC publicou o documento Política Nacional de Educação Infantil: pelo direito das crianças de zero a seis anos à educação que visa orientar os municípios a investirem na Educação Infantil como política pública. As normas anteriores, em 2009 foram substituídas pelo Parecer CNE/CEB n. 20/2009 (BRASIL, 2009a) e a Resolução CNE/CEB n. 5/2009 (BRASIL, 2009b), oriundos de estudos e debates sobre o currículo da Educação Infantil, amplamente discutidas em audiências públicas, com especialistas em Educação Infantil, Professores, Pesquisadores e a participação intensa do MIEIB, por meio dos 27 Fóruns Estaduais de Educação Infantil.

A partir de então, outros documentos foram construídos com objetivo de consolidar a educação infantil, enquanto direito da criança, entre os quais: os Parâmetros Nacionais de Qualidade para a Educação Infantil- Vol. 1 e 2, e os Parâmetros Nacionais de Infra-estrutura para Instituições de Educação Infantil, com o Encarte 1. Estes visam subsidiar os sistemas de ensino na construção de consensos do ponto de vista teórico, político e prático da educação da criança pequena, bem como em adaptações, reformas e construções de espaços para realização da Educação Infantil. Outro documento importante é o Indicadores de Qualidade na Educação Infantil (BRASIL, 2009e), que foi amplamente discutido por meio de um processo participativo e aberto a toda a comunidade e se caracteriza como um instrumento de autoavaliação da qualidade das instituições de educação infantil.

Entre os aportes legais que têm possibilitado implementação dos direitos das crianças de 0 a 6 anos à Educação Infantil-creches e pré-escolas, está a Lei n.11.494/2007, que regulamenta o Fundo de Manutenção e Desenvolvimento da Educação Básica e de Valorização dos Profissionais da Educação (FUNDEB), destinando recursos à Educação Básica- Educação Infantil, Ensino Fundamental e Médio, Educação Especial e Educação de Jovens e Adultos (BROSTOLIN; ROSA, 2014). 
As Leis n. 11.114/05 e n. 11.274/06 que alteraram a LDBEN, antecipando para os 6 anos de idade, a entrada das crianças no ensino fundamental de 9 anos de duração, provocam debates e grandes truculências sobre o corte etário entre educação infantil e o ensino fundamental, assim, a Resolução do CNE/CEB 01/10 (BRASIL, 2010) delibera que as crianças que completam 6 anos de idade até 31 de março, devem ingressar no ensino fundamental, e as que completam 6 anos após o dia 31 de março devem ser matriculadas na Educação Infantil, o que vai ser reafirmado no § 3ำ, do Art. 5o da Resolução CNE/CEB n. 5/2009.

Em continuidade às alterações na Constituição Brasileira, em 2009 foi aprovada a Emenda Constitucional de n. 59/09 (BRASIL, 2009f), que tornou obrigatória a pré-escola para crianças de 4 e 5 anos e estendeu a faixa de obrigatoriedade da educação básica para até 17 anos, com prazo de cumprimento da universalização da oferta de vagas até 2016.

É importante sinalizar que a perspectiva da educação infantil inserida no Sistema de Ensino, evidencia que essa etapa educacional deve ser de responsabilidade de um professor com formação de nível superior, em curso de licenciatura, de graduação plena, em universidades e institutos superiores de educação, admitido o nível médio, na modalidade Normal como formação mínima para o exercício do magistério conforme o Art. 62 da LDBEN.

A Lei n. 11.738, de 16 de julho de 2008, instituiu o piso salarial nacional para professores da Educação Básica pública. Assim, os professores de Educação Infantil passaram a ter direito a um plano de carreira e a todas as conquistas da categoria amparados pela LDB, que equiparou a carreira docente do professor da Educação Infantil ao do professor dos anos iniciais do Ensino Fundamental. Portanto o que se evidencia na história da educação infantil em nosso país é que tivemos avanços no campo do direito à educação, mas ainda temos muitos desafios para efetivar tal direito (BROSTOLIN; ROSA, 2014).

\section{SEGUNDO CENÁRIO: DA INVISIBILIDADE SOCIAL AO PROTAGONISMO DA CRIANÇA COMO SUJEITO DE DIREITOS}

Até por volta do Século XVI, os adultos não haviam conferido o estatuto de criança aos meninos e meninas. A criança era confundida com o adulto e estava sujeita ao poder sem limite deste. As crianças não existiam enquanto uma categoria social, com diferenças, necessidades e direitos separados dos adultos. 
As mudanças na concepção de infância e de criança, ocorrem entre os séculos XVII e XIX, mas é no início do século XX, que começa a se intensificar a defesa dos direitos da criança. Dessa forma, em 1923, temos a elaboração da 1 a Declaração dos Direitos da Criança, chamada de Declaração de Genebra. Essa declaração era composta de cinco princípios gerais, que acentuavam, acima de tudo, a premissa de a "criança em primeiro lugar", aliada à imediata proteção e auxílio.

Em 1959, surge a "Declaração Universal dos Direitos da Criança", cujo texto mantinha-se igual ao de 1923, em relação à proteção das necessidades primárias, mas trazia algumas inovações, tais como: o direito ao nome, nacionalidade e o direito de brincar e a desenvolver-se numa atmosfera de paz e amizade.

Em 1979, Ano Internacional da Criança, temos a "Convenção Internacional dos Direitos da Criança" proposta pelo governo da Polônia e adotada pela Assembleia Geral das Nações Unidas, em 20 de novembro de 1989. A Convenção tinha 54 artigos, entre os quais o direito à educação. No entanto o Brasil, já havia afirmado tal direito, em Constituição Federal um ano anterior à Convenção.

É importante observar que a discussão acerca dos direitos da criança e da infância é relativamente recente e que o fato de ter aparato legal que garante tais direitos, não resolve por si só, pois são necessários os desdobramentos em ações e políticas, mas por outro lado também não implica desrespeito a essas conquistas.

No Brasil, é com a Constituição Federal de 1988, que vamos ver afirmado tal direito, no entanto a sua efetivação, tanto no que se refere a acesso pela população que demanda o atendimento, como também, pela função que essa etapa educacional vai assumir para sua concretização, vem sendo construído no decorrer do final do Século XX e neste início de século XXI.

Entretanto as sociedades foram ficando mais complexas, mundializadas e midiatizadas, e a entrada das crianças em instituições fora de suas famílias foi sendo cada vez mais antecipada. Com isso, a socialização das crianças passa a ocorrer ao mesmo tempo na família e na instituição educativa. É nesta última que ela começa a conviver desde muito pequena, com outros adultos e pares com hábitos, modos de falar e brincar diferentes dos seus.

Pensando a educação infantil nesse contexto, é ali que a criança iniciará a sua vivência em comunidade, aprenderá a respeitar, a acolher, a celebrar a diversidade, a ver o mundo a partir do olhar do outro e terá a compreensão de outros espaços sociais que não os de convivência familiar. Ali ela terá a oportunidade de 
vivenciar práticas sociais que se aprendem através do conhecimento de outras culturas por meio da literatura, da música, da pintura, da dança e das tantas linguagens que ali são exploradas.

Nesse cenário, a educação da criança pequena deixa de ser só uma necessidade dos adultos que convivem com ela, mas passa a ser um direito que ela tem de vivenciar novas formas de aprendizagem que venham a contribuir para o seu desenvolvimento. Esse é o ponto nodal em que se pautam as intensas discussões sobre a educação das crianças pequenas, pois a criança passa a ser o centro das ações nos espaços coletivos que cuidam e educam crianças e, estes, devem constituir-se enquanto instituições educacionais.

Portanto contribui para a constituição desse novo cenário o reconhecimento dos direitos sociais das crianças à educação, bem como os avanços de estudos e pesquisas desenvolvidos nas diversas áreas, tais como sociologia, antropologia e pedagogia. Registra-se então a expansão das matrículas para a faixa etária de zero a seis anos e não podemos deixar de destacar a contribuição dos movimentos sociais, especialmente o das mulheres trabalhadoras que reivindicam vagas junto ao Estado e nas instituições de educação infantil.

A expansão e a institucionalização da educação infantil no Brasil em sua especificidade de primeira etapa da educação básica exige ser pensada na perspectiva da complementaridade e da continuidade, ou seja, os primeiros anos de vida das crianças são momentos de intensas e rápidas aprendizagens. Elas estão chegando ao mundo aprendendo a compreender seu corpo e suas ações, a interagir com diferentes parceiros e, gradualmente, se integrando com e na complexidade de suas culturas ao corporalizá-las (BRASIL, 2009c). Assim, devem receber estímulos contínuos, realizados por professores e em instituições educacionais.

Para além das políticas de educação infantil, é importante pensar em outras políticas quando se trata do atendimento integral à criança, e aqui se incluem aspectos relacionados não só à educação, como também, à saúde, à cultura e à proteção, o que torna necessária a interlocução, com outras áreas dos serviços públicos e outras ações que não são específicas da educação. Portanto, a intersetorialidade é um bom o caminho para garantir o bem-estar de todos: famílias e crianças.

No cotidiano das instituições de educação infantil, a criança deve ter o direito de viver a sua infância e de ser criança. Para tanto, é necessário que a proposta 
pedagógica incorpore e potencialize as relações sociais e as interações que ela estabelece com seus pares e com os adultos, bem como suas experiências, seus saberes, seus modos de produzir, de sentir, de ser, de estar consigo, com o outro e com o planeta.

Na educação infantil, a organização do tempo e do espaço precisa oferecer e oportunizar momentos de troca com outras crianças e de brincadeiras que efetivamente promovam aprendizagens, garantindo o seu desenvolvimento. A situação de compartilhar a educação das crianças traz a necessidade social de um diálogo contínuo entre família, sociedade e escola que precisam determinar o papel de cada uma.

Todas essas questões se acirram quando discutidos os aspectos da obrigatoriedade advinda com a Emenda Constitucional n. 59/2009 (BRASIL, 2009f), pois, na sua implementação, tais aspectos não podem ser deixados de lado quando se refere às crianças de 4 a 6 anos de idade, pois elas são da educação infantil. $\mathrm{E}$, ainda, não se pode perder de vista as crianças de zero a três anos de idade.

No contexto brasileiro, a escola pública ao longo dos seus anos de existência, tem se caracterizado por um processo de seletividade, que atinge de maneira mais acentuada as crianças oriundas das classes populares, alijando-as da educação escolar. Mas não podemos perder de vista que a obrigatoriedade é um avanço na perspectiva de garantia de direito à educação, e não somos contrários a isto, pois, nesse aspecto, pensar a obrigatoriedade dos 4 anos aos 17 anos é considerar um avanço no campo de garantia de direito e de acesso.

\section{TERCEIRO CENÁRIO: A BASE NACIONAL CURRICULAR DA EDUCAÇÃO INFANTIL E O CONTEXTO ATUAL}

Frente ao cenário exposto anteriormente, a educação infantil brasileira nas últimas décadas, vem construindo uma nova concepção sobre o cuidar e educar de crianças de zero a seis anos em instituições educativas. Essa concepção visa romper com o assistencialismo que marca a história da Educação Infantil e o processo escolarizante que antecipa práticas do Ensino Fundamental.

Segundo Barbosa e Richter (2015, p. 189), "no Brasil, em termos de políticas curriculares, as decisões vêm, desde os anos 1990, sendo tomadas em movimentos oscilatórios". Essa afirmação das autoras se fundamenta na argumentação de que as DCNEI de 1999 se caracterizam pela abertura ao apresentar poucos e amplos 
artigos que favoreciam muitas possibilidades curriculares. Mas, ao mesmo tempo, há um endereçamento muito específico dos RCNEI de 1998, que apresenta um currículo por áreas, eixos e faixas etárias.

Entretanto, passados 20 anos, o que permaneceu nas creches e pré-escolas questionam as autoras. Mesmo com a publicação das DCNEI de 2009, que reformulam as diretrizes anteriores e trazem novas concepções, relatórios de pesquisa consultados por Barbosa e Richter (2015) constatam a permanência do discurso dos RCNEl. As autoras acreditam que esse fato se deve à apresentação de um conceito de escola, ensino, de conteúdo, de ação docente muito próximo à compreensão tácita de escola convencional.

Diante desse contexto, delineia-se um movimento em torno de uma base comum para a elaboração de currículos prevista no ordenamento legal da educação básica brasileira, ou seja, na Constituição de 1988, na LDB, Lei n. 9.394/1996 e nas DCN para o Ensino Fundamental e Médio. Essa elaboração também é tratada por quatro das vinte metas do PNE (2014-2024).

Frente ao estabelecido, em março de 2015, a SEB-MEC constituiu um comitê assessor formado por professores universitários de várias regiões do país, e uma equipe de especialistas, composta por professores universitários que atuam em licenciaturas, professores de escola básica e técnicos de secretarias de educação de estados, municípios e distrito federal, sendo estes dois últimos indicados pelo CONSED e UNDIME. Coube, portanto, a esse grupo elaborar a proposta preliminar de direitos e objetivos de aprendizagem e desenvolvimento da BNCC, disponibilizada posteriormente à consulta pública.

Ao longo dos meses de dezembro de 2015 a março de 2016, a equipe de assessores e especialistas acolheu com muito respeito as críticas e contribuições oriundas do debate público, o que permitiu que emergissem em cada área de conhecimento, as principais controvérsias técnicas e políticas a respeito dos currículos. Assim, tornou-se possível elaborar a segunda versão, que articulada as DCNs, exprime entendimentos entre os diferentes segmentos que participaram do debate a respeito de quais devem ser os objetivos de aprendizagem e desenvolvimento fundamentais para cada etapa da Educação Básica.

$\mathrm{Na}$ Educação Infantil, buscou-se pensar uma base nacional comum que rompesse com os modelos tradicionais, organizados por disciplinas, como muitas vezes são encontrados na área. Nesse propósito, dirigiu-se o olhar para a Itália, 
um país que, desde o século XIX, vem contribuindo para a constituição do campo da Educação Infantil, por meio de autores e experiências exitosas que referenciam a Itália como um lugar onde a Pedagogia da escuta, das relações e da diferença para uma escola da infância é um projeto de vida e de formação pessoal vinculado a um projeto de sociedade.

Nessa perspectiva, a organização curricular por Campo de Experiência Educativa abre espaço para os diversos âmbitos do fazer e do agir da criança e abrange aspectos específicos e individualizados de competências nos quais a criança atribui significado às suas múltiplas atividades, desenvolve a sua aprendizagem, adquirindo instrumental linguístico e metodológico; persegue as suas metas formativas na concretude de uma experiência que se desenvolve dentro dos limites definidos e com seu ativo e constante envolvimento.

Pensar novas formas de lidar com os saberes, materiais, tempos e espaços educacionais para crianças pequenas, adotando assim, uma abordagem baseada no escutar ao invés de falar, em que a dúvida e a fascinação são fatores muito bem vindos, junto com a investigação, a descoberta e a invenção. Uma abordagem na qual a importância do inesperado e imprevisto seja reconhecida como forma de a criança participar do processo, possibilitando experiências e processos compartilhados com os professores, as crianças e as famílias.

Portanto acredita-se ser fundamental refletir sobre os campos de experiência no contexto da educação infantil e suas contribuições para pensar o processo de construção de conhecimentos, ou seja, um processo educativo que considere as trocas entre as crianças e entre crianças e adultos. Enfim, pensar um processo educativo que tem na criança a sua centralidade.

Entretanto esse processo democrático que inclui vários avanços conquistados nos últimos anos, passa por um cenário atual de crise econômica e política, especialmente crítica para a educação brasileira e, especificamente, a educação infantil, em virtude da instabilidade e disputa de projetos políticos distintos e conservadores que, embora apresentem uma "legalidade político-jurídica", promovem mudanças não pautadas em princípios democráticos.

Para a concretização da educação infantil brasileira se precisa levar adiante alguns desafios que possuem destaque na agenda prioritária da área, tais como: ampliação na qualidade de atendimento; maiores investimentos financeiros; estabelecimento de um currículo adequado à especificidade da infância; amplia- 
ção das redes; da melhoria da qualidade dos serviços; da efetiva integração aos sistemas de ensino; o estabelecimento de políticas de formação de professores, dentre outros.

Reconhecer a criança em sua vulnerabilidade e globalidade, sujeito histórico, cultural, social e de direitos, exige vencer esses desafios e incluir a educação infantil na educação básica, com legislação educacional específica, sob a responsabilidade de professores habilitados conforme estabelece a Meta 01 do PNE- 2014-2024, e a sociedade brasileira não pode negar à criança esse direito.

\section{ALGUMAS CONSIDERAÇÕES}

Pelo exposto, percebe-se que as instituições de atendimento às crianças pequenas percorreram uma história que comporta, de certa forma, ocorrências de discriminação, equívocos e entendimentos dicotomizados. Ou melhor, como nos apresenta Brostolin e Rosa (2014, p. 29-30) a respeito da Educação Infantil, que "ainda tem sido palco de discussões controversas devido à sua história e às funções higienistas, assistencialistas e compensatórias que Ihes foram atribuídas ao longo do tempo".

Todavia acredita-se na indissociabilidade entre os aspectos de assistência e educação para as crianças pequenas. Desse modo, crê-se que a Educação Infantil continua estabelecendo seu percurso na história, rumo à concretização e efetivação dessa compreensão na(s) sua(s) prática(s).

As mudanças conceituais a respeito da criança, que passaram a considerá-la como ser de direito, têm sido o princípio de toda modificação legal. A creche não é mais um 'direito' da família que precisa de um lugar para deixar o filho. A educação infantil passou a ser direito da criança, de receber uma educação integrada com a família e a comunidade.

Segundo Corsaro (2011), para os adultos é difícil reconhecer que a criança já faz parte da sociedade, há uma tendência em pensar que a infância é um período preparatório para o ingresso da criança na sociedade. Entretanto as crianças já fazem parte da sociedade desde seu nascimento, assim como a infância é parte integrante dela. As crianças são agentes ativos que constroem sua própria cultura, afetam e são afetadas pela sociedade.

No Brasil, o número de documentos oficiais que garantem o direito das crianças à educação se ampliou, nos últimos 30 anos. Esses documentos garantem, 
pelo menos formalmente, o direito das crianças. Falar em direitos é falar em lutas de ideias, projetos e práticas sociais. É falar de grupos e interesses particulares e coletivos em diversos campos em disputa. A educação tem sido um campo de disputa no âmbito dos direitos das crianças.

\section{REFERÊNCIAS}

BARBOSA, M. C.; RICHTER, S. R. Campo de experiência: uma possibilidade de interrogar o currículo. In: FINCO, D.; BARBOSA, M. C.; FARIA, A. L. G. (Org.). Campos de experiência na escola da infância: contribuições italianas para inventar um currículo de educação infantil brasileiro. Campinas, SP: Edições Leitura Crítica, 2015.

BRASIL. Resolução n. 1, de 14 de janeiro de 2010. Brasília: Ministério da Educação, Conselho Nacional de Educação, Câmara de Educação Básica, 2010.

. Ministério da Educação. Conselho Nacional de Educação. Parecer CNE/CEB n. 20, de 11 de novembro de 2009a. Trata da revisão das Diretrizes Curriculares Nacionais para a Educação Infantil. Disponível em: <http://portal.mec.gov.br/index.php?option=com content\&view=article\&id=12745\&ltemid=866>. Acesso em: 31 mar. 2016.

. Ministério da Educação. Conselho Nacional de Educação. Resolução CNE/ CEB n. 5, de 17 de dezembro de 2009b. Fixa as Diretrizes Curriculares Nacionais para a Educação Infantil. Disponível em: <http://portal.mec.gov.br/index.php?catid=323:orgaosvinculados\&id=13684:resolucoes-ceb-009\&option=com_content\&view=article $>$. Acesso em: 31 mar. 2016.

. Secretaria de Educação Básica. Universidade Federal do Rio Grande do Sul. Práticas cotidianas na Educação Infantil - bases para a reflexão sobre as orientações curriculares. Projeto de cooperação técnica MEC e UFRGS para a construção de orientações curriculares para a Educação Infantil. Brasília, 2009c.

. Ensino Fundamental de nove anos: orientações para a inclusão da criança de seis anos de idade. Brasília: Ministério da Educação, Secretaria da Educação Básica, 2009d.

. Indicadores da qualidade na Educação Infantil. Brasília: Ministério da Educação, Secretaria da Educação Básica, 2009e.

. Emenda Constitucional n. 59, de 11 de novembro de 2009. Brasília: Ministério da Educação, Secretária de Educação Básica, $2009 f$.

. Política Nacional para a Educação Infantil: direito das crianças de zero a seis anos à educação. Brasília: Ministério da Educação, Secretaria da Educação Básica, 2006.

. Lei n. 9.394, de 20 de dezembro de 1996. Estabelece as Diretrizes e Bases da Educação Nacional. Presidência da República- Casa Civil. Disponível em: <http://www. planalto.gov.br/CCIVIL/leis/L9394.htm>. Acesso em: 18 maio 2016. 
. Constituição da República Federativa do Brasil. 1988. Disponível em: <http:// www.planalto.gov.br/ccivil_03/constituicao/constituicao.htm>.

BROSTOLIN, M. R.; ROSA, M. F. A instituição de educação infantil: implicações e desafios a partir da inserção no sistema de ensino brasileiro. In: CARMO, J. C.; BROSTOLIN, M. R.; SOUZA, N. M. (Org.). Instituição escolar na diversidade: políticas, formação e práticas pedagógicas. Campinas, SP: Mercado de Letras, 2014.

CORSARO, W. A. Sociologia da infância. Porto Alegre: Artmed, 2011.

KRAMER, S. A política do pré-escolar no Brasil: a arte do disfarce. 9. ed. São Paulo: Cortez, 2011.

\section{Sobre a autora:}

Marta Regina Brostolin: Doutorado em Desenvolvimento Local pela Universidade Complutense de Madri (UCM). Mestrado em Educação - Formação de Professores pela Universidade Católica Dom Bosco (UCDB). Graduação em Pedagogia pela UCDB. Realizou estágio Pós-doutoral na Universidade do Minho, UMINHO, Braga/ Portugal, sob a supervisão do Prof. Dr. Manuel Jacinto Sarmento na especialidade de Sociologia da Infância. Atua no Curso de Pedagogia e Licenciaturas e integra o corpo docente do Programa de Pós-Graduação em Educação - Mestrado e Doutorado da UCDB, pesquisando as temáticas: Formação de Professores; Infância e Educação Infantil. É lider do Grupo de Estudos e Pesquisas da Docência na Infância (GEPDI).E-mail: brosto@ucdb.br

\section{Recebido em fevereiro de 2018 \\ Aprovado em maio de 2018}

